\title{
Does electrical capacitance represent roots in the soil?
}

\author{
Imre Cseresnyés ${ }^{1}[1] \cdot$ Eszter Vozáry $^{2} \cdot$ Kálmán Rajkai $^{1}$
}

Received: 30 October 2019 / Revised: 6 January 2020 / Accepted: 4 April 2020 / Published online: 8 April 2020

(c) The Author(s) 2020

\begin{abstract}
The efficiency of the root capacitance method is still judged contradictorily. It was, therefore, aimed to verify that the electrical capacitance $\left(C_{R}\right)$ and impedance $\left(Z_{R}\right)$ measured between ground electrode (pushed into the soil) and plant electrode (clamped on the stem) really represented the root system present in the soil. An 'electrode separation experiment' and a 'root excision experiment' were performed on potted maize plants cultivated in arenosol. The partial electrical separation of the ground electrode (restriction of the current flow in the topsoil) caused no significant changes in the capacitance and impedance of either the soil or the plant-soil system. This suggested that the current flows through a multitude of soil solution pathways, not predominantly on the wet soil surface. The progressive excision of the main root branches caused a gradual decrease in $C_{R}$ (31-39\% of the initial value) and an increase in $Z_{R}$ (4.4- to 5.2-fold that of intact plants). $C_{R}$ showed a much stronger correlation with root dry mass $\left(R^{2}=0.807\right)$ than with stem cross-sectional area $\left(R^{2}=0.424\right)$ in intact plants. The closeness of the latter relationship decreased further $\left(R^{2}=0.377\right)$ after whole root excision. The results clearly demonstrated that the root system dominated the measured capacitance and impedance, though the role of the stem base was not negligible. In conclusion, the capacitance method is worth considering in future studies as an adequate non-intrusive approach to evaluate root size in the soil.
\end{abstract}

Keywords Electrical capacitance method $\cdot$ Electrical impedance $\cdot$ Root system size $\cdot$ Root excision $\cdot$ Soil dielectrics

\section{Introduction}

The root electrical capacitance $\left(C_{R}\right)$ method is based on the polarization of root membranes, which induces changes in the amplitude and phase of an alternating current (AC) driven through the root system. The $C_{R}$ value detected between the ground and plant electrodes was significantly correlated with the root dry mass (RDM), root length, and surface area (Chloupek et al. 2010). The in situ technique provided reliable estimates of the whole root system size (RSS) or the absorptive root surface area for both pot- and field-grown herbaceous plants and tree saplings (Kormanek et al. 2016; Postic and Doussan 2016; Cseresnyés et al.

Communicated by O. Ferrarese-Filho.

Imre Cseresnyés

cseresnyes.imre@agrar.mta.hu

1 Centre for Agricultural Research, Institute for Soil Sciences and Agricultural Chemistry, Herman Ottó út 15., Budapest 1022, Hungary

2 Department of Physics and Control, Szent István University, Somlói út 14-16., Budapest 1118, Hungary
2018). However, as $C_{R}$ is very sensitive to soil texture and composition, soil water content (SWC), and electrode protocol, data are only comparable for the same species when grown and measured under the same conditions (Chloupek et al. 2010). The great advantage of the method is the possibility of screening numerous plants quickly, and tracking root dynamics by repeated measurements at different phenological stages. The approach is thus ideal for comparison of individuals or genotypes during plant breeding (Svačina et al. 2014), though root morphology cannot be visualized. According to the widely accepted model (Dalton 1995), roots are lossy capacitors (parallel RC circuits), in which root membranes act as dielectrics, separating the conductive root sap and soil solution. The membranes store charges, exhibiting a capacitance proportional to their surface area. Later, Rajkai et al. (2005) proposed a two-dielectric model, which considered the soil capacitance as well.

In contrast, Aulen and Shipley (2012) found the capacitance method unreliable to evaluate RSS in the soil because of the unpredictable effect of external factors on the measured $C_{R}$ value. Furthermore, Kendall et al. (1982) reported that $C_{R}$ of field-grown alfalfa plants reduced significantly but 
only slightly (by $\sim 10 \%$ ) by severing most of the root system; however, detailed methodology for root excision was not provided. Dietrich et al. (2012) reached similar conclusions in their root cutting experiment on hydroponically grown barley. The authors stated that the bulk of the root system made a negligible contribution to $C_{R}$, which was determined by the capacitance of the tissue between the solution surface and the plant electrode. Furthermore, the $C_{R}$ detected was directly proportional to the cross-sectional area (CSA) at the solution surface, and the linear $C_{R}-\mathrm{RSS}$ correlations could only be explained as an allometric relationship between RSS and CSA. They also found that, in soils, only the moisture content in the top layer influenced $C_{R}$, implying that current preferred to pass between the electrodes through the more conductive soil surface instead of through the roots (Dietrich et al. 2013).

Nevertheless, the revised model suggested by Dietrich et al. $(2012,2013)$ contradicts several previous and recent observations. For example, the colonization of maize roots with arbuscular mycorrhizal fungi had no influence on RDM and reduced the root length and surface area, whereas it increased $C_{R}$ due to the enhanced root-soil interface caused by the growth of external hyphae (Cseresnyés et al. 2013). The monitoring of annual crops and young woody species in soil revealed characteristic seasonal changes in $C_{R}$, which were related to the dynamics of whole-plant transpiration and root uptake activity (Psarras and Merwin 2000; Vamerali et al. 2009; Cseresnyés et al. 2018). Likely due to similar reasons, root studies in oilseed plants and young trees showed diurnal patterns in spectral polarization signatures (Weigand and Kemna 2019) and in the magnitude of $C_{R}$
(Ellis et al. 2013b). Kormanek et al. (2016) found a closer correlation between $C_{R}$ and root size parameters for beech seedlings immersed in hydroponic solution when the root systems were flattened between two flat-plate electrodes and then when the roots were freely arranged inside a cylindrical electrode.

These observations can hardly be explained by the dominance of the plant stem base in the resulting $C_{R}$. A pot trial with soil-grown maize was, therefore, undertaken to verify the hypothesis that (1) the current flows between the ground and plant electrodes not only through the soil but also through the roots; and (2) roots play a key role in determining $C_{R}$, confirming the ability of the capacitance method to evaluate RSS in soils.

\section{Materials and methods}

Twelve 2.9 L plastic pots $(14 \mathrm{~cm}$ height, $17 \mathrm{~cm}$ upper diameter) were filled with $4.0 \mathrm{~kg}$ of air-dried, coarsely sieved arenosol ( $80.3 \%$ sand, $12.7 \%$ silt, $7.0 \%$ clay) with a $\mathrm{pH}_{\mathrm{H} 2 \mathrm{O}}$ of $7.21,0.23 \%$ lime content, $1.31 \%$ humus content, and $0.21 \mathrm{~cm}^{3} \mathrm{~cm}^{-3} \mathrm{SWC}$ at field capacity. An open PVC cylinder $(11 \mathrm{~cm}$ outer diameter, $8 \mathrm{~cm}$ height, and $0.2 \mathrm{~cm}$ wall thickness) was installed vertically to a depth of $7 \mathrm{~cm}$ on each pot in an eccentric position (Fig. 1). The pots were watered to field capacity on a balance $( \pm 1 \mathrm{~g})$, and then, a single 2-dayold maize seedling (Zea mays L., composite cross population) was planted at $2 \mathrm{~cm}$ depth in the center of each pot. The plants were cultivated in a growth chamber at $28 / 20^{\circ} \mathrm{C}$ with a $16 \mathrm{~h}$ photoperiod and PAR of $500 \mu \mathrm{mol} \mathrm{m}^{-2} \mathrm{~s}^{-1}$ with

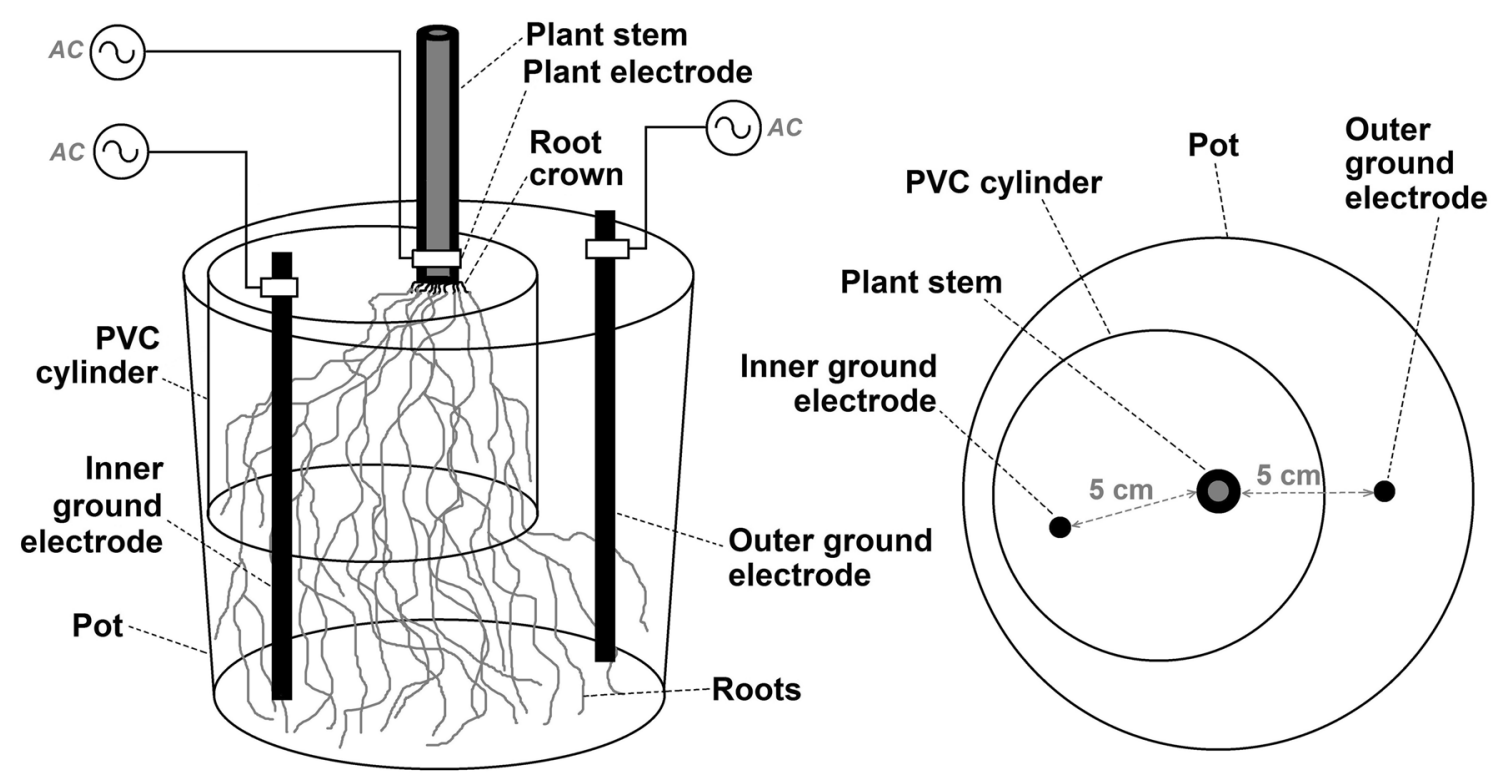

Fig. 1 Scheme of the electrode separation experiment (Exp. 1). See the text for details 
daily irrigation to field capacity. The SWC was checked with a Trime-HD2 TDR meter attached to a Pico32 probe with $11 \mathrm{~cm}$ rod length (IMKO GmbH., Ettlingen, Germany).

The parallel electrical capacitance $\left(C_{R}\right)$ and then, after switching the measurement mode, electrical impedance $\left(Z_{R}\right)$ were detected using a GW-8101G LCR bridge (GW Instek Co. Ltd., Taiwan) at $1 \mathrm{kHz}$ and $1 \mathrm{~V} \mathrm{AC}$. The ground electrode was a sharpened stainless steel rod $(15 \mathrm{~cm}$ length and $0.6 \mathrm{~cm}$ diameter) pushed vertically into the soil to $12 \mathrm{~cm}$ depth $5 \mathrm{~cm}$ from the stem. The plant electrode was clamped at the same height $(1.5 \mathrm{~cm}$ above the soil surface) on each plant through a $0.4 \mathrm{~cm}$ wide aluminum strip that bent the stem. Conductivity gel was smeared under the strip.

Electrode separation experiment (Exp. 1): An hour before the electrical measurement, the soil was adjusted to field capacity (checked with TDR meter) both inside and outside the plastic cylinder in each pot. The cylinder edge above the soil surface was wiped dry to ensure electrical insulation. An 'inner' and an 'outer' ground electrode were positioned inside and outside the cylinder, respectively, both $5 \mathrm{~cm}$ away from the stem (Fig. 1). First, $C_{R}$ and $Z_{R}$ were measured between the plant electrode and the 'inner' ground electrode. The readings were then repeated after relocating the instrument terminal to the 'outer' ground electrode, while the plant electrode was left untouched. Three measurements were taken with both electrode combinations and were averaged for each of the plants on five occasions (at plant ages of 7, 14, 22, 30, and 38 days). Before planting, the electrical capacitance and impedance of the moistened soil $\left(C_{\text {Soil }}\right.$ and $\left.Z_{\text {Soil }}\right)$ were detected using two ground electrodes positioned $5 \mathrm{~cm}$ apart, first with both of them inside and then with one of them outside the PVC cylinder (three measurements per pot). At the end of the experiment, the cylinders were cautiously lifted out of the soil. Paired $t$ tests were performed to assess statistical differences $(p<0.05)$ in $C_{\text {Soil }}, Z_{\text {Soil }}, C_{R}$, and $Z_{R}$ between the 'inner' and 'outer' ground electrode locations for the twelve pots.

Root excision experiment (Exp. 2): All the plants were grown until the 42nd day, when they already have thick crown roots but still no brace roots in contact with the soil. Two perpendicular stem diameters were measured at the soil surface with a digital caliper to determine CSA, after which the plants were tied to wooden sticks to prevent lodging. After checking SWC in the pot, $C_{R}$ and $Z_{R}$ were detected for the intact plant. Keeping both electrodes in contact, a crown root was sought by scraping out the wet soil $1-1.5 \mathrm{~cm}$ away from the edge of the stem. The root branch was excised below the soil level $(\sim 1 \mathrm{~cm})$, the soil was smoothed back carefully, and the LCR meter was read again. By going around the plant, the next crown root was excavated, cut, and buried, followed by the detection of the electrical properties. Root excision and instrumental measurement were continued with the other individual crown roots and then the seminal roots beneath the stem. After the last coarse-root excision, the roots were washed out of the soil over a $0.2-\mathrm{mm}$ sieve (Oliveira et al. 2000), floated (to minimize the loss of fine roots), oven-dried at $70{ }^{\circ} \mathrm{C}$, and weighed $( \pm 0.001 \mathrm{~g})$. The proximal root segments were cut off the root crown, dried and weighed separately. The total RDM was calculated for each plant. The effect of root excision on the $C_{R}$ and $Z_{R}$ values was statistically evaluated with the paired $t$ test. Linear regression was used to relate $C_{R}$ to CSA or RDM.

\section{Results and discussion}

In Exp. $1, C_{\text {Soil }}$ and $Z_{\text {Soil }}$ values of $80.8 \pm 4.9 \mathrm{nF}$ (mean $\pm \mathrm{SD}$; $n=12$ ) and $508 \pm 38 \Omega$, respectively, were measured between the two ground electrodes placed inside the PVC cylinder, while values of $79.9 \pm 4.4 \mathrm{nF}$ and $512 \pm 40 \Omega$ were obtained when one electrode was positioned outside the cylinder. According to the paired $t$ test, both the decrease in $C_{\text {Soil }}$ and the increase in $Z_{\text {Soil }}$ caused by electrode separation were non-significant $(p=0.134,0.203)$. The magnitude of $C_{R}$ increased and that of $Z_{R}$ decreased continuously with plant age due to root development. Electrode separation had no significant influence on $C_{R}$ or $Z_{R}$ at any measurement time (Table 1). The mean rate of change ranged from -1.09 to $1.28 \%$ and from -1.23 to $1.26 \%$ for $C_{R}$ and $Z_{R}$, respectively.

In Exp. 2, the 42-day-old intact plants exhibited $C_{R}$ and $Z_{R}$ values of $8.44-13.54 \mathrm{nF}$ and $3.83-6.18 \mathrm{k} \Omega$, respectively. A total of 10-14 root branches per plant (5-8 crown roots and 4-7 seminal roots) were excised. The root cutting process resulted in a progressive decrease in $C_{R}$ to $3.01-4.52 \mathrm{nF}$ (Fig. 2a), which was $31-39 \%$ of the initial value, and led to a continuous increase in $Z_{R}$ to $17.2-29.8 \mathrm{k} \Omega$ (Fig. 2b), which was 4.4- to 5.2-fold higher than that of intact plants. The paired $t$ test revealed that both $C_{R}$ and $Z_{R}$ changed significantly $(p<0.001)$ even after the first root excision. CSA ranged from 128.6 to $213.1 \mathrm{~mm}^{2}$, and showed only weakly significant, linear correlations with the $C_{R}$ values measured both for the intact plants $\left(R^{2}=0.424 ; F=7.35 ; p=0.022\right)$ and after total root cutting $\left(R^{2}=0.377 ; F=6.06 ; p=0.034\right.$; Fig. 2c). The harvested plants had total RDM values ranging from 2.326 to $4.125 \mathrm{~g}, 4.2-6.8 \%$ of which $(0.106-0.256 \mathrm{~g})$ was composed of the proximal root segments excised from the crown terminally. A highly significant linear relationship was found between $C_{R}$ and the total RDM $\left(R^{2}=0.807\right.$; $F=41.7 ; p<0.001 ;$ Fig. 2 d).

The separation of the two ground electrodes by the PVC cylinder caused no significant differences in the $C_{\text {Soil }}$ or $Z_{\text {Soil }}$ values. This finding directly contradicts the hypothesis that AC flows between the electrodes principally on the wet soil surface. In accordance, the transferal of the ground electrode from the inner to the outer side of the cylinder had no influence on the $C_{R}$ and $Z_{R}$ values measured even for young 
Table 1 Mean \pm SD $(n=12)$ of root electrical capacitance $\left(C_{R} ; \mathrm{nF}\right)$ and root electrical impedance $\left(Z_{R} ; \mathrm{k} \Omega\right)$ detected for maize plants at different ages (DAP: days after planting), including an 'inner ground electrode' (IGE) or an 'outer ground electrode' (OGE) in the measurement circuit (see text for details)

\begin{tabular}{|c|c|c|c|c|c|c|c|c|}
\hline \multirow[t]{2}{*}{ DAP } & \multicolumn{4}{|l|}{$C_{R}(\mathrm{nF})$} & \multicolumn{4}{|l|}{$Z_{R}(\mathrm{k} \Omega)$} \\
\hline & IGE & OGE & $\mathrm{RC} \%$ & $p$ & IGE & OGE & $\mathrm{RC} \%$ & $p$ \\
\hline 7 & $2.10 \pm 0.25$ & $2.13 \pm 0.27$ & 1.28 & 0.173 & $40.74 \pm 3.73$ & $41.23 \pm 3.57$ & 1.26 & 0.135 \\
\hline 14 & $3.68 \pm 0.34$ & $3.70 \pm 0.27$ & 0.61 & 0.643 & $20.91 \pm 2.51$ & $20.68 \pm 2.79$ & -1.23 & 0.238 \\
\hline 22 & $6.45 \pm 0.68$ & $6.38 \pm 0.64$ & -0.89 & 0.224 & $9.56 \pm 1.24$ & $9.62 \pm 1.23$ & 0.75 & 0.449 \\
\hline 30 & $8.96 \pm 0.87$ & $8.88 \pm 1.08$ & -1.09 & 0.363 & $6.16 \pm 0.67$ & $6.09 \pm 0.63$ & -0.88 & 0.282 \\
\hline 38 & $10.57 \pm 1.34$ & $10.63 \pm 1.35$ & 0.60 & 0.375 & $5.16 \pm 0.80$ & $5.19 \pm 0.78$ & 0.66 & 0.386 \\
\hline
\end{tabular}

$\mathrm{RC}(\%)$ shows the rate of change in $C_{R}$ or $Z_{R}$ when the outer ground electrode was attached instead of the inner one. $p$ represents the significance level obtained using paired $t$ tests
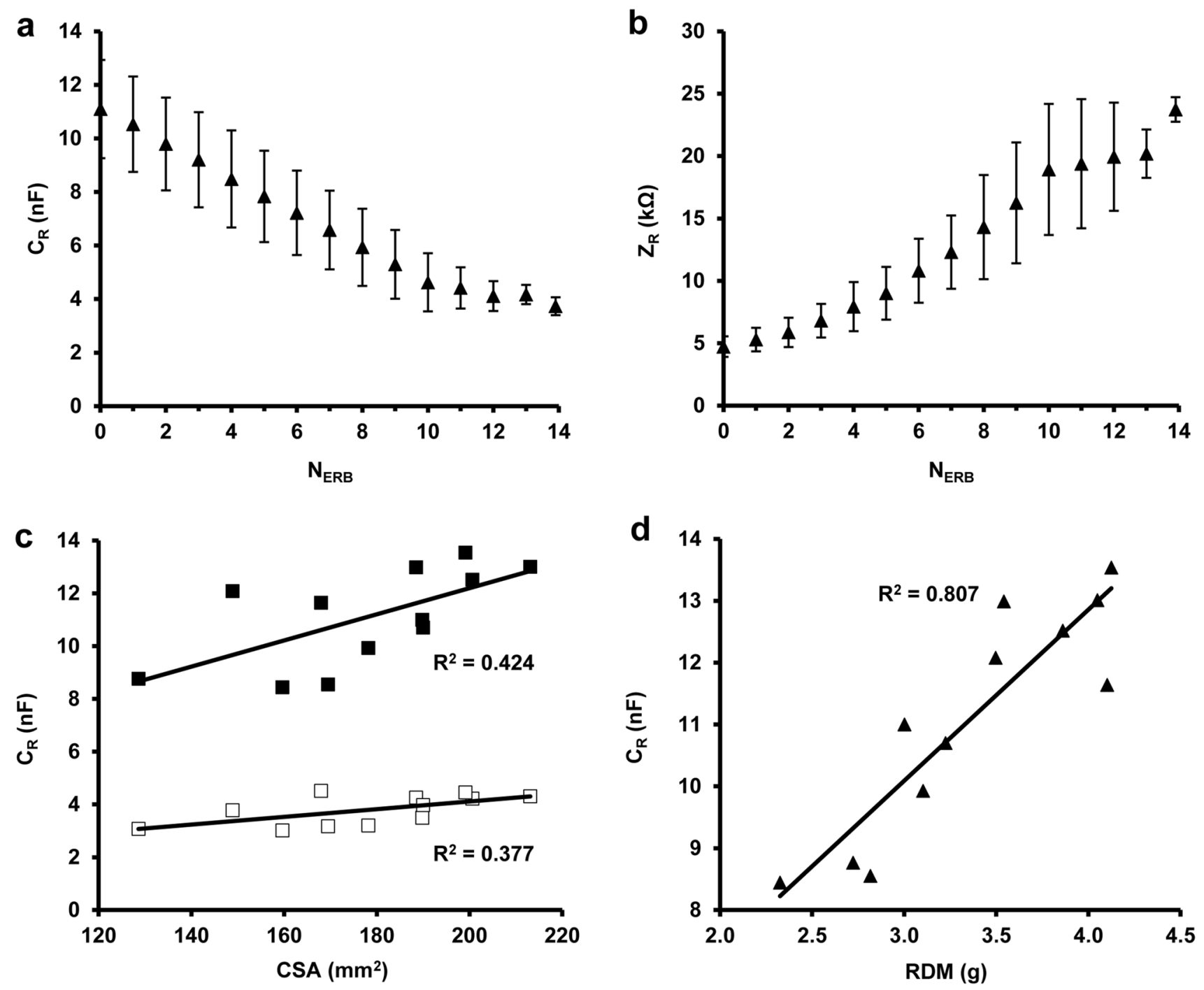

Fig. 2 Changes in a root electrical capacitance $\left(C_{R}\right.$ in $\mathrm{nF}$; mean $\pm \mathrm{SD}$, $n=12)$ and $\mathbf{b}$ root electrical impedance $\left(Z_{R}\right.$ in $\mathrm{k} \Omega$; mean $\left.\pm \mathrm{SD}, n=12\right)$ in relation to the number of excised root branches $\left(N_{\mathrm{ERB}}\right)$ for maize plants. c Relationship between $C_{R}$ and the cross-sectional area of the

stem at the soil surface $\left(\mathrm{CSA} ; \mathrm{mm}^{2}\right)$ for maize plants with intact root systems (filled square; $F=7.35 ; p=0.022$ ) and after root excision (square; $F=6.06 ; p=0.034$ ). d Relationship between $C_{R}$ and total root dry mass (RDM; g) for maize plants $(F=41.7 ; p<0.001)$ 
(7-day-old) plants, whose entire root system probably grew inside the cylinder. These results verify the basic assumption of Dalton's (1995) model, that electric current flows between the electrodes through a multitude of soil solution pathways formed by the structural porosity. A more recent study on canola reported closer relationships between $C_{R}$ and RSS in dry than in wet soil (Wu et al. 2017), which also contradicts the dominant role of the moistened topsoil in conducting electric current.

The gradual drop in $C_{R}$ and rise in $Z_{R}$ with the increasing number of excised root branches clearly demonstrated the significance of the root system in the plant-soil impedance response. The change induced in $C_{R}$ or $Z_{R}$ by cutting a root branch was variable. This was presumably due to differences in anatomy, size (surface area), uptake activity, and conductivity not only between the crown and the seminal roots but also between the individual root branches (Ahmed et al. 2018). Pattern of resource allocation was reported to result close allometric association between shoot and root biomass for maize (Gerardo et al. 2013). In our case, the measured $C_{R}$ showed a much stronger correlation with RDM than with CSA. Additionally, the closeness of the relationship between $C_{R}$ and CSA decreased further when the whole root system was cut off. The same was also true for $Z_{R}$ (data not presented).

These results were similar to those obtained by Čermák et al. (2006). Although they reported a significant allometric relationship between the basal area (stem CSA) and absorbing root surface area for several broadleaf and coniferous tree species, the root severing of Norway spruce supported a direct negative correlation between the measured impedance and the active root surface area. Moreover, a 'root cutting experiment' and a 'progressively immersed root system experiment' involving hydroponically grown spinach and tomato provided evidence that only the root part immersed in the medium contributed significantly to the $C_{R}$ detected (Ozier-Lafontaine and Bajazet 2005).

Opinions still differ on how the various parts of the root system participate in electric conduction and contribute to the measured capacitance. Urban et al. (2011) suggested that, as most of the charge carriers pass through plant tissues near the root neck, the impedance response is predominantly determined by the proximal part of the root-soil interface, and only slightly affected by the distal fine roots. In contrast, Ellis et al. (2013a) showed that most if not the entire length of the root system was electrically connected, so it was the thick proximal roots that had a lesser influence on $C_{R}$. These authors found that the stem and soil impedances were principally resistive and, consequently, the roots represented the main capacitance element in the plant-root-soil system (Ellis et al. 2013a, b). In the present case, the increasing $Z_{R}$ caused by progressive root cutting clearly demonstrated a reduction in the electrically conductive cross-sectional area.
At the end of root excision, the plants exhibited about a third of the initial $C_{R}$ value. As the root stumps left in the crowns represented only $4-7 \%$ of the total RDM (and obviously a negligible part of the total root surface area), the remaining $C_{R}$ was suspected to be the capacitance of the stem base. This finding partially agrees with the revised model offered by Dietrich et al. $(2012,2013)$, and demonstrates that the role of the stem in determining the magnitude of $C_{R}$ is not negligible. The remaining capacitance is thought to be due to the polarization of the epidermal membranes in the root neck and the stem base. The two-dielectric capacitor model assumes that if the soil capacitance is substantially higher than the root capacitance, $C_{R}$ is basically determined by the root system (Rajkai et al. 2005; Dietrich et al. 2012; Kormanek et al. 2016). In the present study, $C_{\text {Soil }}$ for the wet substrate proved to be much higher than $C_{R}$, which met the criteria of this model. Importantly, the dielectric behavior of soils may differ considerably from those of hydroponic solutions due to the presence of surface-charged particles such as colloids, and to water binding by the soil matrix (Hilhorst 1998). The pathways of a low-frequency current driven through a solid substrate-root system are presumably determined jointly by the component resistances and capacitances.

The present experiment did not reveal what proportion of the whole root system was responsible for the resultant $C_{R}$. However, the results convincingly showed that, in contrast to some previous suggestions, the stem base was an important but not dominant component of $C_{R}$ under the given experimental conditions. The findings may necessitate developing improved models for the underlying current pathways. The importance of this is based on the inconsistent results obtained for the role of roots in forming the impedance response.

Although it is true that the electrophysical basis of the stem-root-soil circuit is still poorly understood and requires further comprehensive research, the present study provided strong evidence that the electrical capacitance detected between ground and plant electrodes represented the root system growing in the soil environment. Consequently, this measurement technique should be considered as an adequate tool to assess RSS in situ.

Author contribution statement ICs designed and carried out the experimental work, read the relevant literature, and wrote the paper. EV was responsible for giving biophysical explanations of the present findings. KR supervised the work and helped in data interpretation. All the authors read and improved the manuscript critically and approved the submission. 
Acknowledgements Open access funding provided by Centre for Agricultural Research. This project was financed by the National Research, Development and Innovation Fund of Hungary (NKFIH K-115714), GINOP-2.3.2-15-2016-00028, and a János Bolyai Research Scholarship from the Hungarian Academy of Sciences. The authors thank Barbara Harasztos for language editing.

\section{Compliance with ethical standards}

Conflict of interest The authors declare that they have no conflict of interest.

Open Access This article is licensed under a Creative Commons Attribution 4.0 International License, which permits use, sharing, adaptation, distribution and reproduction in any medium or format, as long as you give appropriate credit to the original author(s) and the source, provide a link to the Creative Commons licence, and indicate if changes were made. The images or other third party material in this article are included in the article's Creative Commons licence, unless indicated otherwise in a credit line to the material. If material is not included in the article's Creative Commons licence and your intended use is not permitted by statutory regulation or exceeds the permitted use, you will need to obtain permission directly from the copyright holder. To view a copy of this licence, visit http://creativecommons.org/licenses/by/4.0/.

\section{References}

Ahmed MA, Zarebanadkouki M, Meunier F, Javaux M, Kaestner A, Carminati A (2018) Root type matters: measurement of water uptake by seminal, crown, and lateral roots in maize. J Exp Bot 69:1199-1206. https://doi.org/10.1093/jxb/erx439

Aulen M, Shipley B (2012) Non-destructive estimation of root mass using electrical capacitance on ten herbaceous species. Plant Soil 355:41-49. https://doi.org/10.1007/s11104-011-1077-3

Čermák J, Ulrich R, Staněk Z, Koller J, Aubrecht L (2006) Electrical measurement of tree root absorbing surfaces by the earth impedance method: 2. Verification based on allometric relationships and root severing experiments. Tree Physiol 26:1113-1121. https ://doi.org/10.1093/treephys/26.9.1113

Chloupek O, Dostál V, Středa T, Psota V, Dvořáčková O (2010) Drought tolerance of barley varieties in relation to their root system size. Plant Breed 129:630-636. https://doi.org/10.111 1/j.1439-0523.2010.01801.x

Cseresnyés I, Takács T, Végh RK, Anton A, Rajkai K (2013) Electrical impedance and capacitance method: a new approach for detection of functional aspects of arbuscular mycorrhizal colonization in maize. Eur J Soil Biol 54:25-31. https://doi.org/10.1016/j.ejsob i.2012.11.001

Cseresnyés I, Szitár K, Rajkai K, Füzy A, Mikó P, Kovács R, Takács T (2018) Application of electrical capacitance method for prediction of plant root mass and activity in field-grown crops. Front Plant Sci 9:93. https://doi.org/10.3389/fpls.2018.00093

Dalton FN (1995) In-situ root extent measurements by electrical capacitance methods. Plant Soil 173:157-165. https://doi.org/10.1007/ BF00155527

Dietrich RC, Bengough AG, Jones HG, White PJ (2012) A new physical interpretation of plant root capacitance. J Exp Bot 63:61496159. https://doi.org/10.1093/jxb/ers264

Dietrich RC, Bengough AG, Jones HG, White PJ (2013) Can root electrical capacitance be used to predict root mass in soil? Ann Bot 112:457-464. https://doi.org/10.1093/aob6mct044
Ellis T, Murray W, Kavalieris L (2013a) Electrical capacitance of bean (Vicia faba) root systems was related to tissue density-a test for the Dalton model. Plant Soil 366:575-584. https://doi. org/10.1007/s11104-012-1424-z

Ellis T, Murray W, Paul K, Kavalieris L, Brophy J, Williams C, Maass M (2013b) Electrical capacitance as a rapid non-invasive indicator of root length. Tree Physiol 33:3-17. https://doi.org/10.1093/ treephys/tps115

Gerardo R, Gutierrez Boem FH, Fernández MC (2013) Severe phosphorus stress affects sunflower and maize but not soybean root to shoot allometry. Agron J 105:1283-1288. https://doi.org/10.2134/ agronj2013.0123

Hilhorst MA (1998) Dielectric characterisation of soil. Doctoral Thesis, Wageningen Agricultural University, The Netherlands

Kendall WA, Pederson GA, Hill RR (1982) Root size estimates of red clover and alfalfa based on electrical capacitance and root diameter measurements. Grass Forage Sci 37:253-256. https:// doi.org/10.1111/j.1365-2494.1982.tb01604.x

Kormanek M, Głąb T, Klimek-Kopyra A (2016) Modification of the tree root electrical capacitance method under laboratory conditions. Tree Physiol 36:121-127. https://doi.org/10.1093/treephys/ tpv088

Oliveira MRG, van Noordwijk M, Gaze SR, Brouwer G, Bona S, Mosca G, Hairiah K (2000) Auger sampling, ingrowth cores and pinboard methods. In: Smit AL, Bengough AG, Engels C, van Noordwijk M, Pellerin S, van de Geijn SC (eds) Root methods: a handbook. Springer, Berlin, pp 175-210

Ozier-Lafontaine H, Bajazet T (2005) Analysis of root growth by impedance spectroscopy (EIS). Plant Soil 277:299-313. https:// doi.org/10.1007/s11104-005-7531-3

Postic F, Doussan C (2016) Benchmarking electrical methods for rapid estimation of root biomass. Plant Methods 12:33. https:// doi.org/10.1186/s13007-016-0133-7

Psarras G, Merwin IA (2000) Water stress affects rhizosphere respiration rates and root morphology of young 'Mutsu' apple trees on M-9 and MM.111 rootstocks. J Am Soc Hortic Sci 125:588-595

Rajkai K, Végh RK, Nacsa T (2005) Electrical capacitance of roots in relation to plant electrodes, measuring frequency and root media. Acta Agron Hung 53:197-210. https://doi.org/10.1556/ AAgr.53.2005.2.8

Svačina P, Středa T, Chloupek O (2014) Uncommon selection by root system size increases barley yield. Agron Sustain Dev 34:545551. https://doi.org/10.1007/s13593-013-0160-y

Urban J, Bequet R, Mainiero R (2011) Assessing the applicability of the earth impedance method for in situ studies of tree root systems. J Exp Bot 62:1857-1869. https://doi.org/10.1093/jxb/erq370

Vamerali T, Bandiera M, Coletto L, Zanetti F, Dickinson NM, Mosca G (2009) Phytoremediation trials on metal- and arsenic-contaminated pyrite wastes (Torvicosa, Italy). Environ Pollut 157:887894. https://doi.org/10.1016/j.envpol.2008.11.003

Weigand M, Kemna A (2019) Imaging and functional characterization of crop root systems using spectroscopic electrical impedance measurements. Plant Soil 435:201-224. https://doi.org/10.1007/ s11104-018-3867-3

Wu W, Duncan RW, Ma B-L (2017) Quantification of canola root morphological traits under heat and drought stresses with electrical measurements. Plant Soil 415:229-244. https://doi.org/10.1007/ s11104-016-3155-Z

Publisher's Note Springer Nature remains neutral with regard to jurisdictional claims in published maps and institutional affiliations. 